\title{
Association Between IL-17, IL-8 and IL-18 Expression in Peripheral Blood and Helicobacter Pylori Infection in Mongolian Gerbils
}

\author{
Yan-Rong Zhao ${ }^{1}$; Yan Zhou ${ }^{2}$; Gang Lin ${ }^{2}$; Wei-Jian Hu ${ }^{1}$; Ji-Mei Du ${ }^{2, *}$ \\ ${ }^{1}$ Department of General Surgery, the First Affiliated Hospital, Wenzhou Medical University, Wenzhou, China \\ ${ }^{2}$ School of Laboratory Medicine, Wenzhou Medical University, Wenzhou, China \\ *Corresponding author: Ji-Mei Du, School of Laboratory Medicine, Wenzhou Medical University, Wenzhou, China. Tel:+86-57786699299, Fax: +86-57786689779, E-mail: jimeidu123@163.com
}

Received: June 24, 2014; Revised: August 9, 2014; Accepted: August 28, 2014

\begin{abstract}
Background: Persistent Helicobacter pylori infection confers an increased risk for serious illnesses such as peptic ulcers and gastric cancer. Various cytokines are involved in the regulation of inflammatory immune response in H.pylori-infected gastric mucosa.

Objectives: The current study aimed to obtain evidence regarding the association between IL-17, IL-8 and IL-18 expression in peripheral blood and H. pylori infection in Mongolian gerbils.

Materials and Methods: Mongolian gerbils were inoculated with H. pylori by a metal stomach catheter. After sacrifice, their gastric mucosae were examined in macroscopic, histological and electron microscopy levels. In addition, enzyme linked immunosorbent assay (ELISA) assay was performed on the IL-17, IL-8 and IL-18 cytokines in the blood samples.

Results: Serum levels of IL-17, IL-8 and IL-18 were remarkably up-regulated compared to those of the control group. There was an obvious correlation between the increase of IL-17 and the serious extent of gastritis in the current study. However, the serum levels of IL-8 and IL-18 without getting increasingly more for repetitive intragastric administration. There were plenty of neutrophils infiltrating in the infected group mucosal. Intestinal metaplasia and gastric ulcers were also founded in H. pylori infected animals after enhanced inoculation. The edema, degeneration and necrosis changes could be found in organelles by transmission electron microscopy. More serious pathological changes were detected in the enhanced inoculation groups compared to the cycle group.

Conclusions:The serum levels of IL-17, but not IL-8 and IL-18 may serve as a potential biomarker for diagnosis and predicting the prognosis of gastritis caused by H.pylori.
\end{abstract}

Keywords: IL-17; Inflammation; Helicobacter pylori

\section{Background}

Helicobacter pylori have infected nearly half of the world's population. In the developing countries, more than $90 \%$ of adults are typically infected during their early childhood, and once acquired the infection would last for several decades (1). Helicobacter pylori infection is the main cause of gastritis and persistent chronic inflammation may lead to peptic ulcers or gastric cancer (2-4). Helicobacter pylori gastritis is associated with the expression of various cytokines and immune cells infiltration (1). It is recently demonstrated that IL-17, IL-8 and IL-18 are associated with $H$. pylori-related gastritis diseases (5-7). Recently, it is found that IL-17, a pro-inflammatory cytokine that can recruit neutrophils by inducing the production of CXC chemokines, plays a vital role in the inflammatory response to the $H$. pylori-related diseases (8). Furthermore, it is also reported that IL-17, IL-8, and IL18 are important to maintain the chronic gastric inflammation in the Mongolian gerbils model induced by the H. pylori (8-10). Considering that up-regulation of IL-17,
IL-8 and IL-18 plays a crucial role in H. pylori infection, it was explored that the expression of IL-17, IL-8 and IL-18 in peripheral blood may be involved in the inflammatory response to $H$. pylori.

\section{Objectives}

The current study aimed to obtain evidence regarding the association between serum levels of IL-17, IL- 8 and IL18 and the stomach pathological changes induced by $H$. pylori infection in Mongolian gerbils.

\section{Materials and Methods}

\subsection{Animals}

Three-week-old male specific pathogen-free Mongolian gerbils were purchased from Wenzhou Medical University Animal Experiment Center/China (approximately $25 \mathrm{~g}$ ). They were kept in polypropylene cages on

Copyright (C) 2015, Ahvaz Jundishapur University of Medical Sciences. This is an open-access article distributed under the terms of the Creative Commons Attribution-NonCommercial 4.0 International License (http://creativecommons.org/licenses/by-nc/4.0/) which permits copy and redistribute the material just in noncommercial usages, provided the original work is properly cited. 
saw dust bedding in groups of two per cage, and caged under a LD 12:12 cycle. The animals used in the current study were cared for according to the institutional guidelines. The experimental protocol was approved by the animal care and use committee of Wenzhou medical university/China.

\subsection{Bacterial Inoculation and Helicobacter pylori Colonization}

Helicobacter pylori NCTC 11637 was provided by Prof. Jie Yan. The bacteria were cultivated in Columbia agar (OXOID England) with 10\% sheep blood (Wenzhou Kont biology and technology, LTD, China) for two to three days at $37^{\circ} \mathrm{C}$ under microaerobic conditions $\left(15 \% \mathrm{CO}_{2}\right)$ and high humidity, on a shaker at $100 \mathrm{rpm}$. After fasting, animals were inoculated every other day for three counts with $1 \mathrm{~mL}$ medium of $H$. pylori (109 CFU/ml) using a metal stomach catheter as one cycle. Animals had free access to food and water after administration for four hours. Infection was supported by urease test and culture. Mongolian gerbils were considered $H$. pylori positive when urease test and culture were positive. The infection rate in the inoculated animals was $100 \%$.

\subsection{Experimental Design}

Mongolian gerbils were randomly divided into four groups ( $n=6$ in each). The control group was inoculated into three counts of Columbia agar medium. Groups A, B and C were firstly inoculated by gavage with $H$. pylori NCTC 11637 for one cycle. Group A was enhanced inoculation for one count. Group B was enhanced inoculation for two counts, and group $\mathrm{C}$ was enhanced inoculation for three counts after the first inoculation. All the animals were sacrified under anesthesia at 35 weeks. Immediately after scarifying, the stomach was quickly removed and used for macroscopic, histological and electron microscopy examinations. Developed gastritis was diagnosed according to histological scores. Moreover, the serum was obtained and stored at $-20^{\circ} \mathrm{C}$. The serum levels of IL-17, IL- 8 and IL-18 were measured using an ELISA Kit (Invitrogen, Carlsbad, CA, USA) according to the manufacturer's instructions. All results were reported as means $\pm \mathrm{SD}$. Differences between the groups were tested by an ANOVA with subsequent Scheffe post-hoc test and the relationship between IL and gastritis serious were tested using Spearman test. The statistical analysis was performed by SPSS version 16.0. The level of statistical significance was always set at $\mathrm{P}<0.05$.

\section{Results}

The assessment was performed for inflammation, neutrophil infiltrate, mucosal atrophy and intestinal meta- plasia using the semi quantitative scales (-, none; + , mild; ++, moderate; +++, severe) of the updated Sydney system (11) (Table 1).

The results of the analysis showed the correlation between enhance inoculation counts and gastritis serious. The serum levels of IL-17, but not IL-8 and IL-18 showed a correlation with the severity of gastritis (Figure 1)

The current study showed that the serum levels of IL17 , IL-8 and IL-18 obviously increased compared to those of control group. Moreover, it indicated that the serum levels of IL-17 continuously increased after repetitive intragastric administration of $H$. pylori and were obviously correlated with the severity of gastritis. However, the serum levels of IL-8 and IL-18 were up-regulated after intragastric administration of $H$. pylori for one cycle and without increase after intragastric administration (Figure 2).

The gastric mucosa of the control group and group A showed no visible changes. In group B, the stomach had several small ulcers and mucosa expanded and thickened slightly. In group C, erosive lesions with more ulcers were detected, covered by abundant mucus (Figure 3)

Histology examination was taken in the gastric mucosa of Mongolian gerbils. In the control group, inflammatory cell infiltration in the lamina propria was inconspicuous. In group A, the gastric mucosa showed slight histological changes. The length of fundic mucosa decreased and the pyloric mucosa expanded. The normal gland cells disappeared, leaving elongated pseudopyloric glands with a little of mucins in the transitional zone mucosa. In the lamina propria of the pyloric mucosa, moderate amount of inflammatory infiltrating cells was observed. In group B, the histological changes were evident. Small erosions were found in the pyloric mucosa. The submucosa also located similar mucous glands surrounded by interstitium with a conspicuous infiltration of lymphocytes. In group C, several ulcers were found near the transitional zone and some of them reached the muscularis propria. In the vicinity of transitional mucosa between pylori and fundic mucosa large erosion was observed, which consisted of numerous inflammatory cells (Figure 4).

Electron microscopy observation was conducted on the Mongolian gerbils gastric mucosa. In the control group, no obvious pathological changes were found in the gastric mucosa. In group A, the nucleus showed mild pyknosis, mild expansion could be observed in rough endoplasmic reticulum, and the mitochondria edema could be observed in cellular. Moreover, gastric mucosa microvilli showed edema and falling off. In group B, the nucleus showed pyknosis and deformation, the mitochondria vacuoles appeared, and the mucus particles of glands epithelial cells became fusion and aggregation. In group C, the nucleus showed pyknosis. Gap of nuclear membrane and rough endoplasmic reticulum expanded, the edema, degeneration and necrosis could be observed in mitochondria (Figure 5). 
Zhao Yetal.

Table 1. Histological Findings in Gastric Mucosa in Helicobacter pylori-Infected Mongolian Gerbils a,b

\begin{tabular}{|c|c|c|c|c|c|c|c|c|c|c|c|c|c|c|c|c|}
\hline & \multicolumn{4}{|c|}{ Control } & \multicolumn{4}{|c|}{ Group A } & \multicolumn{4}{|c|}{ Group B } & \multicolumn{4}{|c|}{ Group C } \\
\hline & - & + & ++ & +++ & - & + & ++ & +++ & - & + & ++ & +++ & - & + & ++ & +++ \\
\hline Inflammation & 6 & 0 & 0 & 0 & 1 & 3 & 2 & 0 & 0 & 2 & 3 & 1 & 0 & 0 & 4 & 2 \\
\hline $\begin{array}{l}\text { Neutrophil } \\
\text { infiltrate }\end{array}$ & 6 & 0 & 0 & 0 & 1 & 3 & 2 & 0 & 0 & 3 & 3 & 0 & 0 & 1 & 4 & 1 \\
\hline Atrophy & 6 & 0 & 0 & 0 & 4 & 1 & 1 & 0 & 3 & 2 & 1 & 0 & 0 & 3 & 2 & 1 \\
\hline $\begin{array}{l}\text { Intestinal } \\
\text { metaplasia }\end{array}$ & 6 & 0 & 0 & 0 & 6 & 0 & 0 & 0 & 5 & 1 & 0 & 0 & 2 & 3 & 1 & 0 \\
\hline
\end{tabular}

a Note. $\mathrm{n}=$ number of animals; -=none; +=mild;++= moderate; +++= severe.

$\mathrm{b}$ For control and the other groups $(\mathrm{n}=6)$.

Figure 1. The Correlation Between Enhanced Inoculation Counts and Developed Gastritis

A

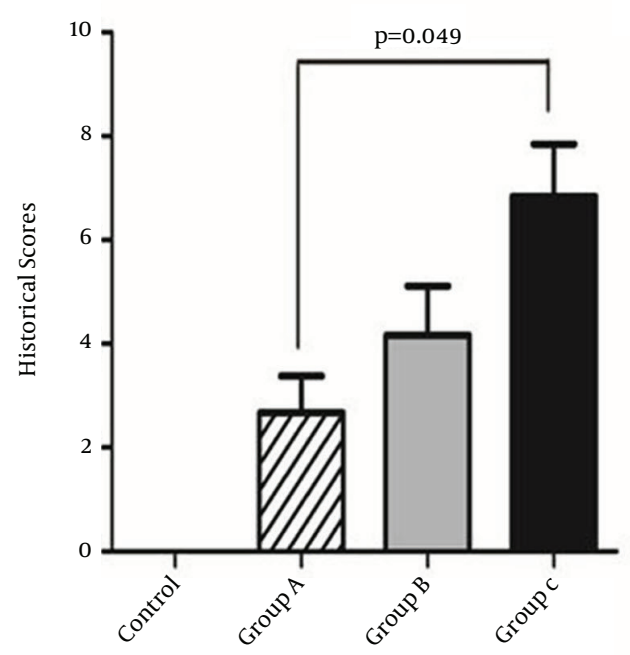

C

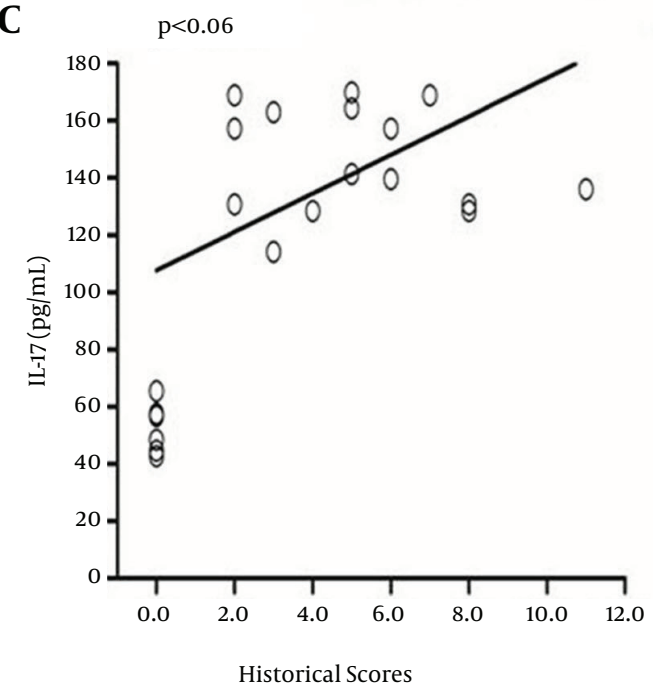

B

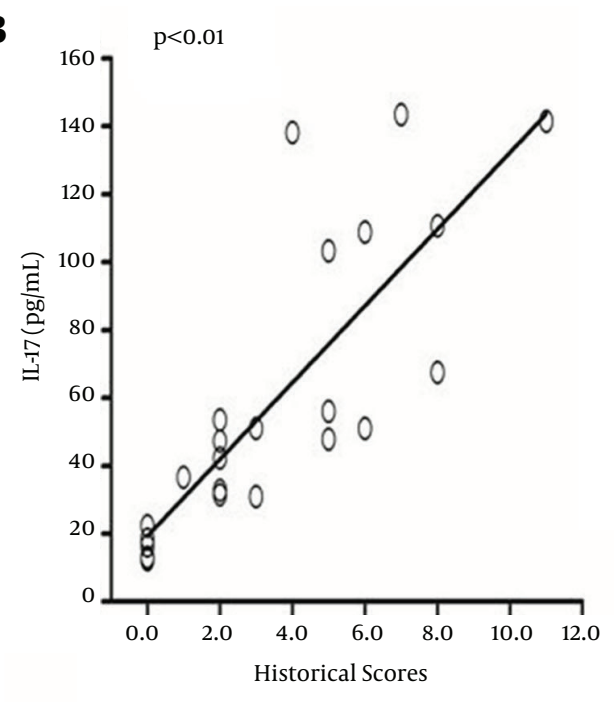

D

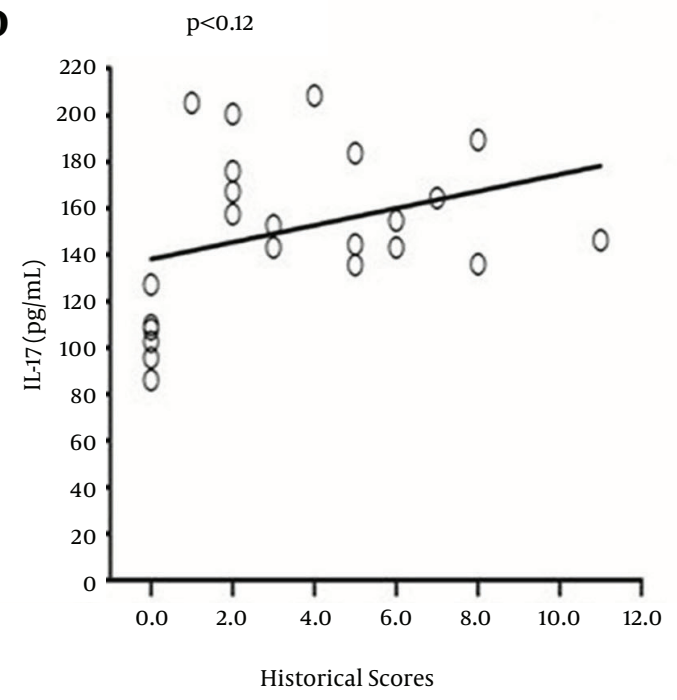

There was a correlation between serum levels of IL-17 and the degree of gastritis. 
Zhao Yet al.

Figure 2. Serum Levels of IL-17, IL-8 and IL-18 in Different Groups

A

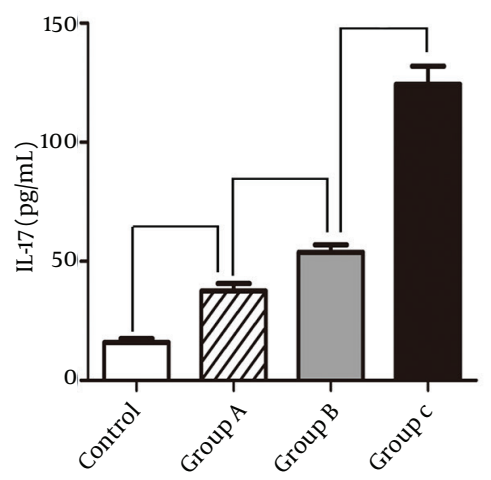

B

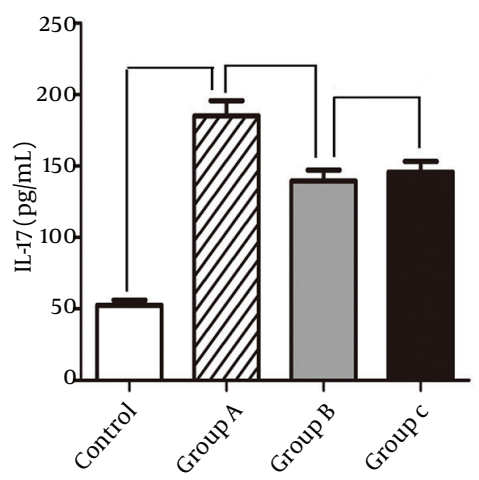

C

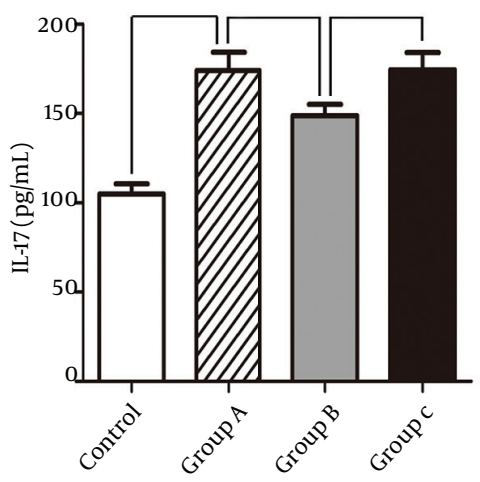

A: IL-17; B: IL-8; C: IL-18.

Figure 3. Macroscopic Observation of Mongolian Gerbil Stomach
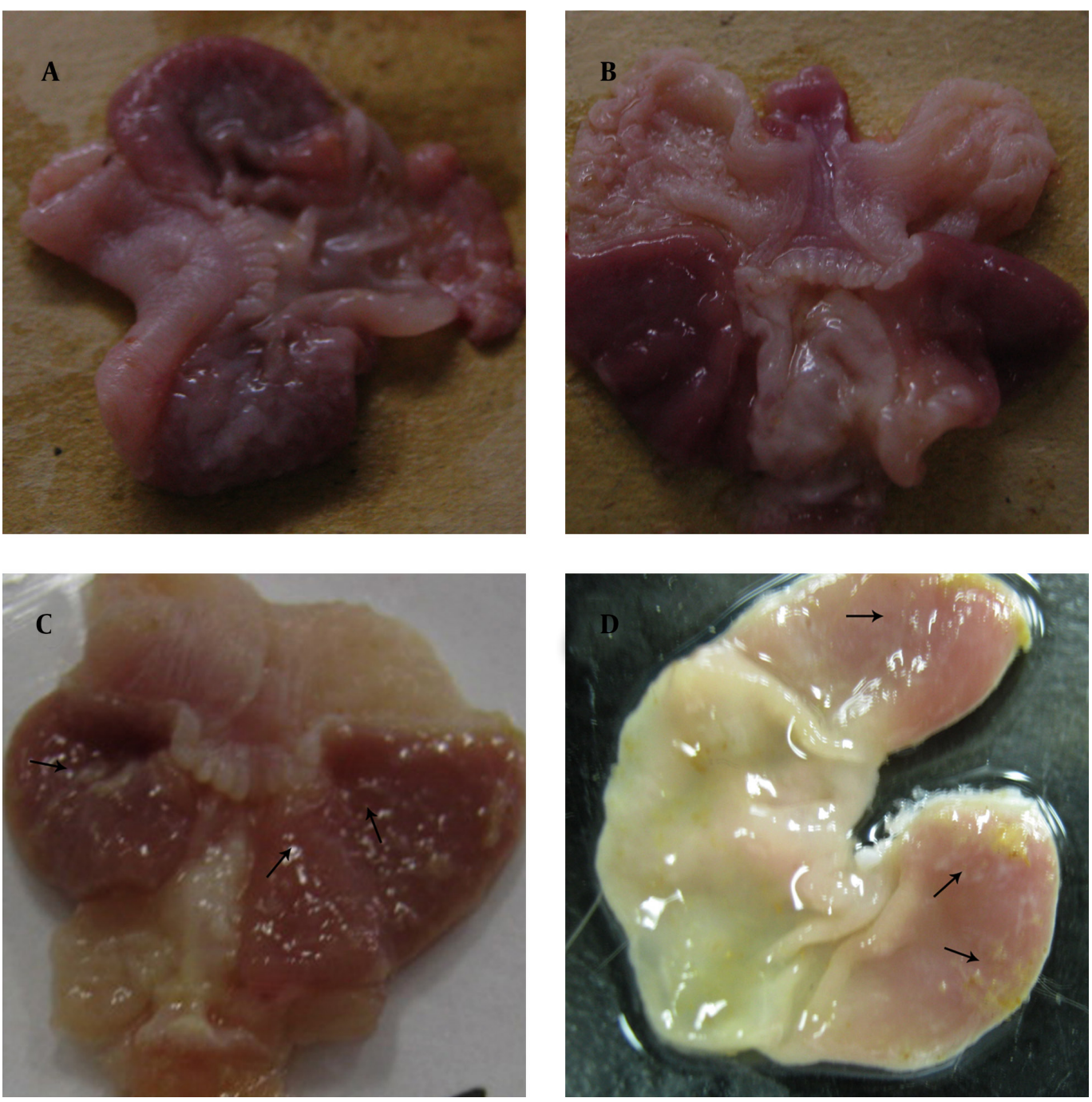

A: control group; B: group A; C: group B; antral mucosa slightly expanded and several ulcers were detected (arrows); D: group C; mucosa was covered by abundant mucus (arrows). 
Zhao Yet al.

Figure 4. Histology Findings of Mongolian Gerbil Stomach
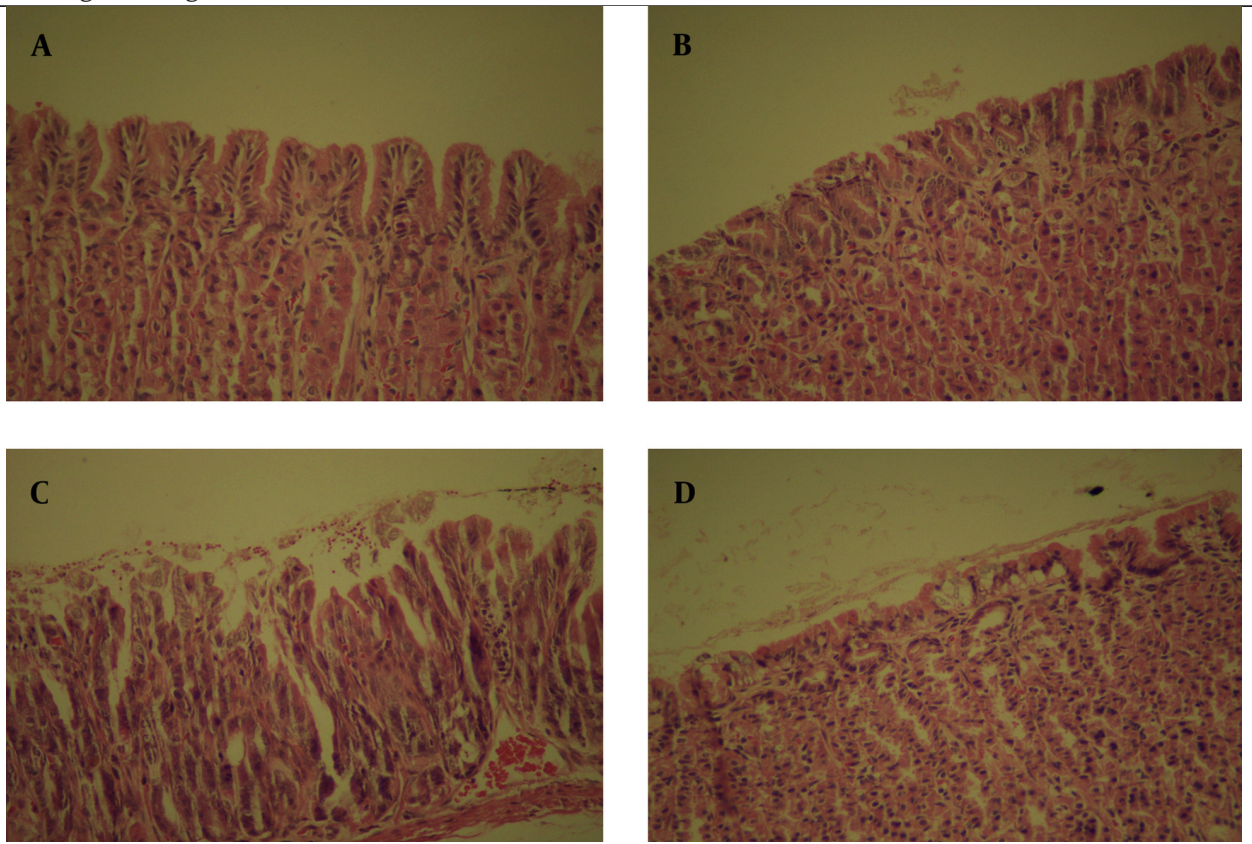

A: control group; B: group A; few neutrophils infiltrated the epithelium in the transitional zone; C: group B; erosion was observed; D: group C; the glandular structures were damaged (H \& E x400).

Figure 5. Electron Microscopy Observation on Epithelial Cells of Gastric Mucosa
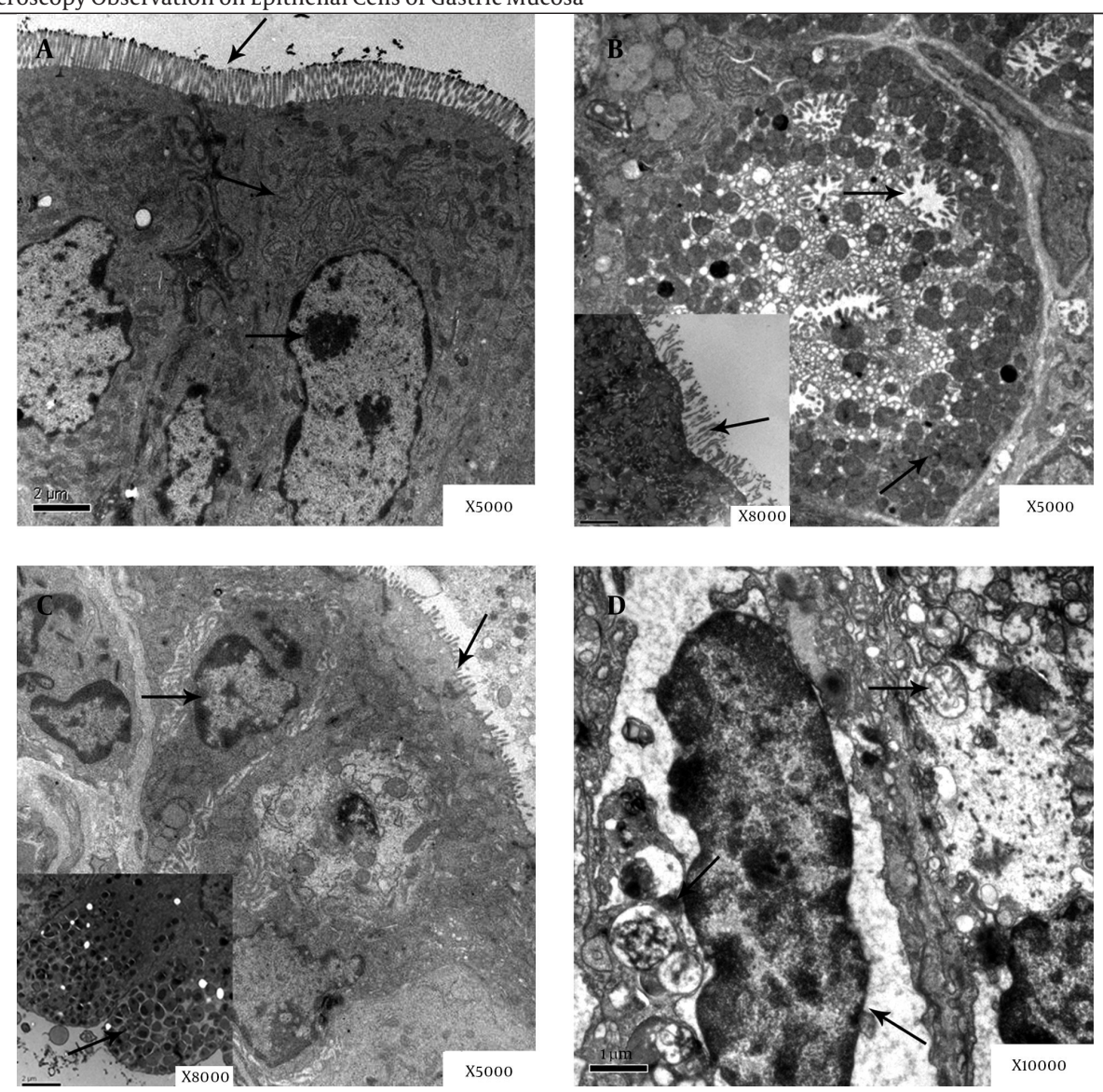

A: control group; no pathological changes were found. B: group A; the gastric mucosa microvilli edema and falling off (arrows); C: group B. the mucus particles of glands epithelial cells became fusion and aggregation (arrows); D: group C; autophagosome and autophagic vacuoles formatiom (arrows). 


\section{Discussion}

In the present study, it was known that the regulation of cytokines in the gastric mucosa plays a significant role in the H. pylori infections such as IL-17, IL-6, IL-8, IL-18, and TNF- $\alpha(1,5,9,10,12)$. Mongolian gerbils are perfect animals to study gastric disease pathogenesis details $(13,14)$. The current research enriches the cytokine profiles of the chronic phases of H. pylori infections. To the authors` best knowledge, there are no reports on the serum levels of IL17, IL-8, IL-18 and the gastric mucosa pathological changes to date. Helicobacter pylori infections in the Mongolian gerbils induced an antral-predominant gastritis and gradually progressed to the whole corpus $(14,15)$. Some mucosal cytokines expression was paralleled with the acute inflammation such as IL-1 $\beta$ (16). In addition, gastric corporal mucosal chronic inflammation was paralleled with IFN- $\gamma$ expression (17).

Pro-inflammatory gene activity was highly sublimated and the risk of gastric disease was promoted for the increased inflammatory cytokines. IL-17 as an emerging family member expressed in the T memory cells plays a key role in the pathogenesis of some chronic inflammatory diseases (18-20). IL-17 can also stimulate the expression level of IL-8 and facilitate the chemotaxis of neutrophils $(20,21)$. Some clinical studies found that the levels of IL-17 increased in gastric mucosa of the patients infected with H. pylori (20). It was also known that the gastric mucosal levels of IL-17 increased in Mongolian gerbils with $H$. pylori infection, especially in the chronic inflammatory phase $(8,18-20)$. Up to now, almost all investigators only focused on studying the gastric mucosal levels of IL and the mRNA expression. The current study focused on studying the serum levels of IL-17 and it was confirmed to be bound up with the amount of neutrophils as well as the development of gastric disease. Numerous small ulcers appeared in the animals stomach and mucosa expanded and thickened slightly in the macroscopic observation.

An obvious neutrophils infiltration on the background of chronic inflammation could be perceived by the ordinary microscope and the edema, degeneration and necrosis in subcellular organelles could be observed through electron microscopy. The contemporaneous appearance of pathology changes and IL-17 level suggest that the inflammation of cells infiltration may be linked to the serum cytokines levels. These results suggest that IL-17 plays a significant role in the inflammatory response to $H$. pylori infection and may serve as a potential biomarker to diagnose and predict the chronic active gastritis. The IL-8 gene is located at chromosome $4 \mathrm{q}$ 13-q21. IL- 8 acts as a chemo attractant which could enhance the migration of neutrophils and leukocytes, and regulate the processes of chronic inflammation (22). It is also engaged in human gastric cancer cells adhesion, migration, and invasion in vitro (23) and highly expressed in gastric cancer cells (24). Yamaoka Y, et al. reported that IL-8 and IL-18 are associated with $H$. pylori-related gastritis diseases
$(5,7)$. The current study also demonstrated that IL-8 was a marked up regulation compared with the control group, and the increased serum levels of IL-8 may not promote the inflammatory response. IL-18 as a member of IL-1 superfamily induced by IFN- $\gamma$ was correlated with the severity of gastric inflammation $(25,26)$.

Some researchers reported that IL-18 is important to maintain the chronic gastric inflammation in the Mongolian gerbils model induced by the H. pylori (8-10). However, other studies indicated that the mRNA levels of IL-18 are independent of $H$. pylori infections $(25,27)$. In the current study, the serum levels of IL-18 increased in $\mathrm{H}$. pyloriinfected Mongolian gerbils. However, the serum levels of IL-18 were not correlated with counts of enhanced inoculation or the severity of pathology changes. Therefore, in order to understand the role of IL-18 in human H. pylori infections further studies are needed.

In conclusion, the current study results demonstrated that the serum levels of IL-17, IL-8 and IL-18 play significant roles in the progression and regulation of Mongolian gerbils with $H$. pylori infections. Moreover, the serum levels of IL-17 differed among each group of animals, and depended on the severity of gastritis disease. Therefore, IL-17 might be related to the gastritis clinical prognosis and be used as a marker to predict the prognosis. However, in order to understand more correlation of the cytokines in $H$. pylori infections additional studies are required.

\section{Acknowledgements}

This study was supported by funds from the science technology department of Zhejiang Province/China and Wenzhou Municipal Sci-Tech Bureau.

\section{Authors' Contributions}

Yan-Rong Zhao and Yan Zhou: laboratory examinations; JD and GL: statistical analysis, study design, and results interpretation; JD and WH: writing of the manuscript. All authors provided comments and approved the final manuscript.

\section{Financial Disclosure}

The authors have declared that there is no conflict of interest.

\section{Funding/Support}

Funding for this work was provided by the Science Technology Department of Zhejiang Province (No. 2009F80012) and Wenzhou Municipal Sci-Tech Bureau/ China, Project (No. H20110025).

\section{References}

1. Yamaoka Y, Kita M, Kodama T, Sawai N, Kashima K, Imanishi J. Induction of various cytokines and development of severe mucosal inflammation by cagA gene positive Helicobacter pylori strains. Gut. 1997;41(4):442-51. 
Zhao Yetal.

2. Salama NR, Hartung ML, Muller A. Life in the human stomach: persistence strategies of the bacterial pathogen Helicobacter pylori. Nat Rev Microbiol. 2013;11(6):385-99.

3. Sun YQ, Soderholm JD, Petersson F, Borch K. Long-standing gastric mucosal barrier dysfunction in Helicobacter pylori-induced gastritis in mongolian gerbils. Helicobacter. 2004;9(3):217-27.

4. Sun YQ, Petersson F, Monstein HJ, Soderholm JD, Rehfeld JF, Borch K. Long-term morpho-functional development of Helicobacter pylori-induced gastritis in Mongolian gerbils. Scand J Gastroenterol. 2005;40(10):1157-67.

5. Yamaoka Y, Kita M, Kodama T, Sawai N, Kashima K, Imanishi J. Expression of cytokine mRNA in gastric mucosa with Helicobacter pylori infection. Scand J Gastroenterol. 1995;30(12):1153-9.

6. Bamford KB, Fan X, Crowe SE, Leary JF, Gourley WK, Luthra GK et al. Lymphocytes in the human gastric mucosa during Helicobacter pylori have a T helper cell 1 phenotype. Gastroenterol. 1998;114(3):482-92.

7. Yamaoka Y, Yamauchi K, Ota H, Sugiyama A, Ishizone S, Graham DY, et al. Natural history of gastric mucosal cytokine expression in Helicobacter pylori gastritis in Mongolian gerbils. Infect Immun. 2005;73(4):2205-12.

8. Kabir S. The role of interleukin-17 in the Helicobacter pylori induced infection and immunity. Helicobacter. 2011;16(1):1-8.

9. Sugimoto M, Ohno T, Graham DY, Yamaoka Y. Gastric mucosal interleukin-17 and -18 mRNA expression in Helicobacter pyloriinduced Mongolian gerbils. Cancer Sci. 2009;100(11):2152-9.

10. Pan XF, Wen Y, Loh M, Wen YY, Yang SJ, Zhao ZM, et al. Interleukin-4 and -8 gene polymorphisms and risk of gastric cancer in a population in Southwestern China. Asian Pac J Cancer Prev. 2014;15(7):2951-7

11. Dixon MF, Genta RM, Yardley JH, Correa P. Classification and grading of gastritis. The updated Sydney System. International Workshop on the Histopathology of Gastritis, Houston 1994. Am J Surg Pathol.1996;20(10):1161-81.

12. Tu E, Ang DK, Bellingham SA, Hogan TV, Teng MW, Smyth MJ, et al Both IFN-gamma and IL-17 are required for the development of severe autoimmune gastritis. Eur J Immunol. 2012;42(10):2574-83.

13. Karita M, Li Q, Cantero D, Okita K. Establishment of a small animal model for human Helicobacter pylori infection using germfree mouse. Am J Gastroenterol. 1994;89(2):208-13.

14. Hirayama F, Takagi S, Yokoyama Y, Iwao E, Ikeda Y. Establishment of gastric Helicobacter pylori infection in Mongolian gerbils. Gastroenterol.1996;31 Suppl 9:24-8.

15. Marshall BJ, Warren JR. Unidentified Curved Bacilli in the Stomach of Patients with Gastritis and Peptic Ulceration. Lancet. 1984;323(8390):1311-5.
16. Hwang IR, Kodama T, Kikuchi S, Sakai K, Peterson LE, Graham DY, et al. Effect of interleukin 1 polymorphisms on gastric mucosal interleukin 1beta production in Helicobacter pylori infection. Gastroenterology. 2002;123(6):1793-803.

17. Okamura H, Tsutsi H, Komatsu T, Yutsudo M, Hakura A, Tanimoto T, et al. Cloning of a new cytokine that induces IFN-gamma production by T cells. Nature. 1995;378(6552):88-91.

18. Serrano C, Wright SW, Bimczok D, Shaffer CL, Cover TL, Venegas A et al. Downregulated Th17 responses are associated with reduced gastritis in Helicobacter pylori-infected children. Mucosal Immunol. 2013;6(5):950-9.

19. Kimang'a A, Revathi G, Kariuki S, Sayed S, Devani S, Vivienne M et al. IL-17A and IL-17F gene expression is strongly induced in the mucosa of H. pylori-infected subjects from Kenya and Germany. Scand J Immunol. 2010;72(6):522-8.

20. Luzza F, Parrello T, Monteleone G, Sebkova L, Romano M, Zarrilli R, et al. Up-Regulation of IL-17 Is Associated with Bioactive IL-8 Expression in Helicobacter pylori-Infected Human Gastric Mucosa. J Immunol. 2000;165(9):5332-7.

21. Sebkova L, Pellicano A, Monteleone G, Grazioli B, Guarnieri G, Imeneo $\mathrm{M}$, et al. Extracellular signal-regulated protein kinase mediates interleukin 17 (IL-17)-induced IL-8 secretion in Helicobacter pylori-infected human gastric epithelial cells. Infect Immun. 2004;72(9):5019-26.

22. Kitadai Y, Takahashi Y, Haruma K, Naka K, Sumii K, Yokozaki H, et al. Transfection of interleukin-8 increases angiogenesis and tumorigenesis of human gastric carcinoma cells in nude mice. $\mathrm{Br} J$ Cancer.1999;81(4):647-53.

23. Crabtree JE, Wyatt JI, Trejdosiewicz LK, Peichl P, Nichols PH, Ramsay N, et al. Interleukin-8 expression in Helicobacter pylori infected, normal, and neoplastic gastroduodenal mucosa. J Clin Pathol.1994;47(1):61-6.

24. Ju D, Sun D, Xiu L, Meng X, Zhang C, Wei P. Interleukin-8 is associated with adhesion, migration and invasion in human gastric cancer SCG-7901 cells. Med Oncol. 2012;29(1):91-9.

25. Tomita T, Jackson AM, Hida N, Hayat M, Dixon MF, Shimoyama T, et al. Expression of Interleukin-18, a Th1 cytokine, in human gastric mucosa is increased in Helicobacter pylori infection. J Infect Dis. 2001;183(4):620-7.

26. Sakai K, Kita M, Sawai N, Shiomi S, Sumida Y, Kanemasa K, et al. Levels of interleukin-18 are markedly increased in Helicobacter pylori-infected gastric mucosa among patients with specific IL18 genotypes. JInfect Dis. 2008;197(12):1752-61.

27. Kawabata T, Ichikura T, Majima T, Seki S, Chochi K, Takayama E, et al. Preoperative serum interleukin-18 level as a postoperative prognostic marker in patients with gastric carcinoma. Cancer 2001;92(8):2050-5. 